\section{PRESCRIPTION DRUG OVERDOSE: ENVIRONMENTAL AND BEHAVIOURAL RISKS IN HOMES WITH AND WITHOUT CHILDREN}

${ }^{1}$ Andrea Gielen, ${ }^{1}$ Eileen McDonald, ${ }^{1}$ Wendy Shields, ${ }^{2}$ Alene Kennedy-Hendricks, ${ }^{2}$ Beth McGinty, ${ }^{2}$ Colleen Barry. ${ }^{1}$ Johns Hopkins Centre for Injury Research And Policy and Centre for Mental Health and Addiction Policy Research; ${ }^{2} J$ ohns Hopkins Bloomberg School of Public Health Policy and Centre for Mental Health and Addiction Policy Research

\subsection{6/injuryprev-2016-042156.379}

Background According to a UN panel, prescription drug abuse will soon exceed illicit drug use worldwide. In the US, opioid pain relievers (OPRs) are widely available, and overdose deaths have increased. Children are vulnerable to either or both unintentional and intentional exposure to OPRs. Little is known about the environmental and behavioural risks associated with storage and disposal of these drugs in homes with children.

Methods We addressed this gap by completing an on-line survey of a nationally representative sample of 1,032 adults who had taken an OPR within the year preceding the survey. Environmental and behavioural risks examined by the presence and ages of children in the home were characteristics of the product, storage location, disposal plans and practices, and beliefs about safe storage.

Results One-third of the sample had children younger than 18 living in the home; $47 \%$ were still using the OPR at the time of the survey. Homes with children compared to those without were significantly more likely to have a child resistant cap on the medication $(91 \%$ vs $78 \%)$ and to store the OPR most often in a place that was locked or latched, although the rates were low in both groups (27\% vs $17 \%$ ). Almost $40 \%$ of those who were no longer using the medication reported keeping it for future use, and only $5 \%$ reported turning the pills in to a take-back program. When asked about storage behaviours, adults with young children compared to those with older children/teens were significantly more likely to have positive beliefs about the benefits and higher perceived threats, and to report fewer barriers to safe storage.

Conclusions The high rates of unsafe storage and disposal of OPRs in homes with children is alarming because of the associated risks of unintentional or intentional exposure of children to these dangerous medications. Campaigns that focus on the risks to older children/teens and increasing the availability of take-back programs in communities are urgently needed.

\section{BUILDING EPIDEMIOLOGICAL CAPACITY FOR DRUG OVERDOSE SURVEILLANCE IN THE U.S. HEALTH DEPARTMENTS}

\begin{abstract}
${ }^{1,2}$ Svetla Slavova, ${ }^{1,3}$ Jennifer Sabel, 1,4 James W Davis, 1,5Dagan Wright, ${ }^{1,6}$ Denise Paone. ${ }^{1}$ Council of State and Territorial Epidemiologists Overdose Subcommittee, USA; ${ }^{2}$ Kentucky Injury Prevention and Research Centre, USA; ${ }^{3}$ Washington State Department of Health, USA; ${ }^{4}$ New Mexico Department of Health, USA; ${ }^{5}$ Oregon Health Authority - Department of Public Health, USA ; ${ }^{6}$ New York City Department of Health and Mental Hygiene, USA
\end{abstract}

\subsection{6/injuryprev-2016-042156.380}

Background In response to the growing prescription drug overdose (DO) epidemic in the U.S., an Injury Surveillance Workgroup on Poisoning (ISWP) released Consensus Recommendations for National and State Poisoning Surveillance in April 2012. The ISWP proposed standardised tools to conduct and improve DO surveillance.

Methods The Council of State and Territorial Epidemiologists (CSTE) formed an Overdose Subcommittee (OS) to raise CSTE membership awareness of DO deaths and to test the proposed DO indicators before they were widely adopted as surveillance tools.

Results The CSTE OS aims and results have been discussed during monthly calls opened to all CSTE members. Several major projects were completed with voluntary participation from CSTE OS members. Analysis of death certificate (DC) data in 11 jurisdictions revealed variations in completeness and specificity of the drug-related information (e.g., DO death rates not contributed to any drug varied from $0 / 100,000$ in New York City to 7.4/ 100,000 in Kentucky). A study using toxicology and DC data found that drug-specific sensitivity on DCs in three jurisdictions varied widely (23\%-92\% benzodiazepines, 61\%-92\% heroin, 91\%-100\% opioid analgesics). New epidemiological tools for DC data analysis were developed. Several jurisdictions worked successfully with medical examiners/coroners to improve completeness and specificity of drugs listed on DCs. The CSTE findings were presented at national conferences, published in papers, and informed the development of national guidelines for state special emphasis reports on DO death data.

Conclusions The CSTE OS work is an ongoing learning process that already improved the DO mortality surveillance methodology and standardisation, increased the epidemiological capacity for DO reporting and data quality improvement at state and local levels, and strengthened the collaborations among epidemiologists from different jurisdictions.

\section{Occupational Safety}

\section{Parallel Wed 1.4}

\section{AN INVESTIGATION OF THE STATE OF OCCUPATIONAL SAFETY AND HEALTH IN THE PHILIPPINES}

Jinky Leilanie Lu. National Institutes of Health, University of the Philippines Manila, Philippine

\subsection{6/injuryprev-2016-042156.381}

Background This study looked into the state of occupational health and safety in the country. Specifically, the objectives were 1) to show the current condition of workers, both local and migrant, in terms of their workplace condition and hazard exposures; and 2) to present occupational diseases and illnesses in various industries and occupational groupings in the Philippines.

Methods The methodology consisted of comprehensive analysis of records and statistics on occupational safety and health, and related variables from various institutions. Data were gathered from reviews of literatures, related research studies, and documentary research at the Occupational Safety and Health Centre. Analysis of data was done through a critical appraisal of the current status of occupational and health safety in the Philippines in terms of occupational diseases, injuries, and accidents, and existing occupational health and safety policies.

Results The study showed occupational hazards and health and safety conditions in various industries, occupational settings, and job groupings such as in the industrial sector, manufacturing, mining, agriculture, fishing, and cement manufacturing. In the industrial sector, particularly, in nine cement plants in the Philippines, workers were noted to be exposed to hazards such as heat, noise and dust. In the electronics sector, about 57 Filipino women were afflicted by Stevens-Johnson Syndrome (SJS) in two electronic factories in Taiwan. Another study of 399 female 
workers in a semiconductor manufacturing industry reported abnormal health effects of hazard exposure such as abortion, ectopic pregnancy, or stillbirth. In four textile establishments in the Philippines showed high concentration of cotton dust, high level of noise in the weaving areas, and toxic chemicals in bleaching, dyeing, printing and finishing processes. Women in the garment industry were found to be exposed to extreme heat, dust from textile fibres, and ergonomic hazards. In a study conducted in major leather tanneries in the Philippines, results showed that tanneries were unhygienic, damp, with pungent odour, had poor housekeeping, and practiced improper disposal of chemicals. Workers were not given personal protective equipment even when handling toxic chemicals such as sulfuric and formic acids, ammonia, and chromium. In the mines, workers reported of being hit by falling objects, suffocation from chemical fumes, and crushing injuries. The study also looked into small scale and informal industries such as tanning, laundry shops, pyrotechnique manufacturing and the like. Special segments of the labour force including the women workers, child labourers and migrant workers were also covered. In all these sectors and industries, the study showed attendant occupational diseases and injuries arising from occupational hazards.

Conclusions The study tried to show more complete data on occupational health and safety in the Philippines considering that there is insufficient collection of OHS data by concerned government agencies.

\section{ASSESSMENT OF OCCUPATIONAL SAFETY SITUATION IN READY-MADE GARMENT SECTOR OF BANGLADESH}

Kaniz Fatema Tuz Zahura, Farzana Islam, Saidur Rahman Mashreky. Centre for Injury Prevention and Research, Bangladesh (CIPRB)

\subsection{6/injuryprev-2016-042156.382}

Background The Ready-made Garment (RMG) industry is Bangladesh's greatest contributor to gross domestic product growth and has played a significant role in the country's improved performance against world development indicators. The industry represents 75 percent of Bangladesh exports and employs almost 4 million people. For this large number of population occupational safety is a major concern. This study was conducted to assess the current occupational safety situation of RMG sector.

Methods The study was conducted in 10 RMG of Dhaka district since June to September 2014 by utilising qualitative and quantitative methods. 10 Focus Group Discussions (FGDs) and 390 face to face interviews using structured questioner were conducted with workers.

Results Qualitatively it was revealed that all 10 factories had workers' welfare committee; they provided counselling on occupational safety and arranged training program on health safety issues. According to the participants there were supervisors in each working unit whose responsibility was to remind them about wearing musk, hand gloves, needle guard and uniform. From quantitative data it was found that $86 \%$ of total participants received counselling related to job during joining. Among them $81 \%$ received information on occupational safety, $54 \%$ on cleanliness and $27 \%$ on nutrition. Among all the participants $41 \%$ received training on fire safety, $21 \%$ general wellbeing and only $6 \%$ received on first aid. $88 \%$ of the participants said they saw different safety related posters including fire safety, personal protection equipment, hygiene and first aid.

Conclusions Occupational safety is now a major concern for readymade garments sector of Bangladesh. They emphases on counselling session during joining and some emergency training program but on much selected topics. Now they need to focus on situation base training and ensure the participation of every worker in this type of programme.

\section{INCIDENCE AND INJURY PATTERNS AMONG ELECTRONIC WASTE WORKERS IN INFORMAL SECTOR IN IBADAN, NIGERIA}

${ }^{1}$ Chimere Ohajinwa, 'Willie Peijnenburg, ${ }^{2}$ Oladele Osibanjo. 'Leiden University, The Netherlands; ${ }^{2}$ University of Ibadan, Nigeria

\subsection{6/injuryprev-2016-042156.383}

Background Electronic waste (e-waste) are an electrical and electronic device that are unwanted by the original owner, and are at the end of their useful life. Large quantities of e-waste are being managed in Nigeria using rudimentary techniques by informal ewaste workers(repairers and dismantlers) who work without personal protective equipment(PPE) or safeguard to their health and environment. Therefore this study assessed the incidence and patterns of work-related injuries among e-waste workers in informal sector in Ibadan, Nigeria.

Methods This cross-sectional study adopted a multi-stage sampling method to select 89 respondents. Questionnaire was used to obtain information from the respondents. This study reports injury among e-waste workers one week preceding the study.

Results Mean age of respondents was $33.9 \pm 11.3$ years, $98.9 \%$ of the participants were males, and $78.7 \%$ had post-primary education; repairers were $53.9 \%$ and dismantlers $46.1 \%$. Thirty-five $(39.3 \%)$ workers sustained at least an injury within one week of the study. Common types of injuries sustained were cuts (40.4\%), bruises/contusions $(22.5 \%)$ and electric shock (18\%). Injuries were mainly caused by sharps (62.9\%), electric current $(20.2 \%)$ and blunt trauma (17\%). Majority of injuries (80.9\%) occurred on the hands/fingers. About 41\% (37) of workers reported using PPE and of these $58.3 \%$ used PPE because of safety concerns. Types of PPE used were dedicated work clothes (67.6\%) and gloves (5.4\%). A higher proportion of dismantlers (48.5\%) than the repairers $(33.3 \%)$ sustained an injury $(p<0.05)$. There was no significant difference in the incidence of injuries among workers who use PPE (40.5\%) compared to those who do not use PPE (38.5\%).

Conclusions There was a high incidence of work-related injuries among the workers studied. Inappropriate handling of e-waste predisposes e-waste workers to risk of injuries. Comprehensive interventions need to be instituted to reduce the incidence of work-related injuries among the workers.

\section{OCCUPATIONAL HEALTH AND SAFETY IN BANGLADESH: AN IMPORTANT CAUSE AND CONSEQUENCE OF EXTREME POVERTY}

Owasim Akram. Independent Researcher, Bangladesh

10.1136/injuryprev-2016-042156.384 